\title{
Pregnancy with Ovarian Dysgerminoma : An Unusual Diagnosis
}

\author{
Dr. Manisha Jain ${ }^{1}$, Dr. C. Budhwani ${ }^{1}$, Dr. Ajay K. Jain ${ }^{2}$, Dr. R.A.Hazari ${ }^{3}$ \\ ${ }^{1}$ Department of Obstertrics and Gynaecology, ${ }^{2}$ Department of Surgery, ${ }^{3}$ Department of Pathology, \\ People's College of Medical Sciences and Research Centre, Bhopal, M.P. India.
}

\section{Introduction:}

Ovarian tumors are broadly classified into three types based on their origin, epithelial, sex cord and germ cell tumors. While epithelial variety largely predominate, germ cell tumors (GCTs) are rare, comprising about $30 \%$ of all ovarian neoplasms and $3 \%$ of all ovarian malignancies. ${ }^{1}$ Ovarian Germ cell tumors, derived from the primordial germ cells, are further divided into subgroups based on the histological features. Mature teratoma being the commonest benign variety while dysgerminoma are the commonest malignant germ cell tumor. ${ }^{2}$ Among the non-dysgerminoma group are yolk sac tumors, endodermal tumors, immature teratoma , embryonal carcinoma, choriocarcinoma and mixed germ cell tumors.

The major challenge with dysgerminoma, the commonest malignant variety of germ cell tumor, is that they predominantly affect young women. About $75 \%$ of dysgerminoma occur between the ages of 10 and 30 years and thus can affect the fertility or may be associated with pregnancy. ${ }^{1} \mathrm{We}$ present one such case of dysgerminoma associated with pregnancy.

\section{Case summary:}

A 25 year old woman, P1L1 was admitted with abdominal distension and generalized abdominal discomfort since the preceding fortnight. She gave history of two month amenorrhea followed by variable amount of bleeding for which she underwent dilatation and evacuation at a peripheral rural centre by local practitioner few days back. Ultrasound documentation of intrauterine pregnancy corresponding to seven weeks of gestation was available which also reported a left adnexal mass with ascitis. There was no history of fever, acute abdominal pain, vomiting or fainting episode. There were no bladder or bowel complaints. Her last child birth was term vaginal delivery two years back. Her past medical history was non contributory. On examination, her general condition was satisfactory. She was afebrile. Her radial pulse was regular, normovolumic with a rate of 84 beats per minute. Her blood pressure in right arm was 120/80 mm of $\mathrm{Hg}$ in supine position. There was mild pallor. There was no icterus or palpable lymphadenopathy. Her respiratory examination revealed bilateral reduced air entry in basal zones with stony dull note on percussion. On per abdominal examination, there was gross distension with stretched out overlying skin. The umbilicus was everted. An 18 week size diffuse mass was felt arising from pelvis more on left side with ill defined margins due to presence of tense ascitis. Fluid thrill could be elicited. There were no dilated veins and all hernia orifices appeared normal. On percussion there was dull note over most of the abdomen. Vulval odema was noted on inspection of genitalia. On per speculum examination cervix was swollen and congested, no discharge though. On bimanual per vaginal examination uterus was parous sized, mobile and firm in consistency. The mass was felt through left fornix, ballotable and separate from the uterus. Cervical movement was non tender.

A provisional diagnosis of P1L1 with left adnexal mass (most probably ovarian) with ascitis with abortion was made.

Her baseline investigations were all within normal limits except mildly elevated erythrocyte sedimentation ratio. The mantoux test was negative. Her chest X-ray showed presence of bilateral minimal pleural effusion. The repeat ultrasonography at our hospital revealed a large cystic lesion of left ovary measuring $15 \times 17 \mathrm{cms}$ with multiple septations and some solid components noted eccentrically with moderate ascitis. The right ovary and adnexal structures appeared normal. The uterine cavity was empty with thin lined endometrium suggestive of complete abortion. The contrast enhanced computed tomography of whole abdomen revealed presence of a large cystic lesion with multiple septations arising from left ovary with presence of moderate ascitis and bilateral pleural effusion. A diagnostic tapping of ascitic fluid was done which was negative for malignant cell, acid fast bacilli or any other organisms. Her papinaculae smear was negative for dysplasia or malignancy. Her serum CA125 levels were $233.20 \mathrm{U} / \mathrm{ml}$ and serum lactate dehydrogenase levels were $539 \mathrm{U} / \mathrm{L}$ (Reference range < 247). The serum $\beta$-hCG levels were $2558 \mathrm{mIU} / \mathrm{ml}$ while $\alpha$-fetoprotein $(\mathrm{AFP})$ levels were $3.29 \mathrm{ng} / \mathrm{ml}$.

An exploratory laparotomy was planned after informed consent. On opening the abdomen about 7 liter of straw colored ascitic fluid was drained which was sent for cytological examination. A large, approximately $18 \times 15 \mathrm{cms}$, left ovarian mass twisted on its pedicle was noted. There were flimsy omental adhesions to the 
mass which were carefully separated. A thorough inspection of peritoneum, liver surface and omentum was done. There were no peritoneal deposits or palpable lymph nodes. The surface of the uterus, right tube and ovary appeared normal. Left tube and ovary were removed along with the mass. Ovarian cystic fluid was sent for cytological examination while the whole mass with left tube and ovary were sent for histopathological examination. Omental biopsy and paraarotic lymph node sampling was done which were negative for malignancy. Surgeons were called for assistance and expert opinion. After ensuring adequate hemostasis, abdomen was closed in layers. Her postoperative recovery was uneventful with suture removal done on postoperative day 8 . Pt was discharged in good condition.

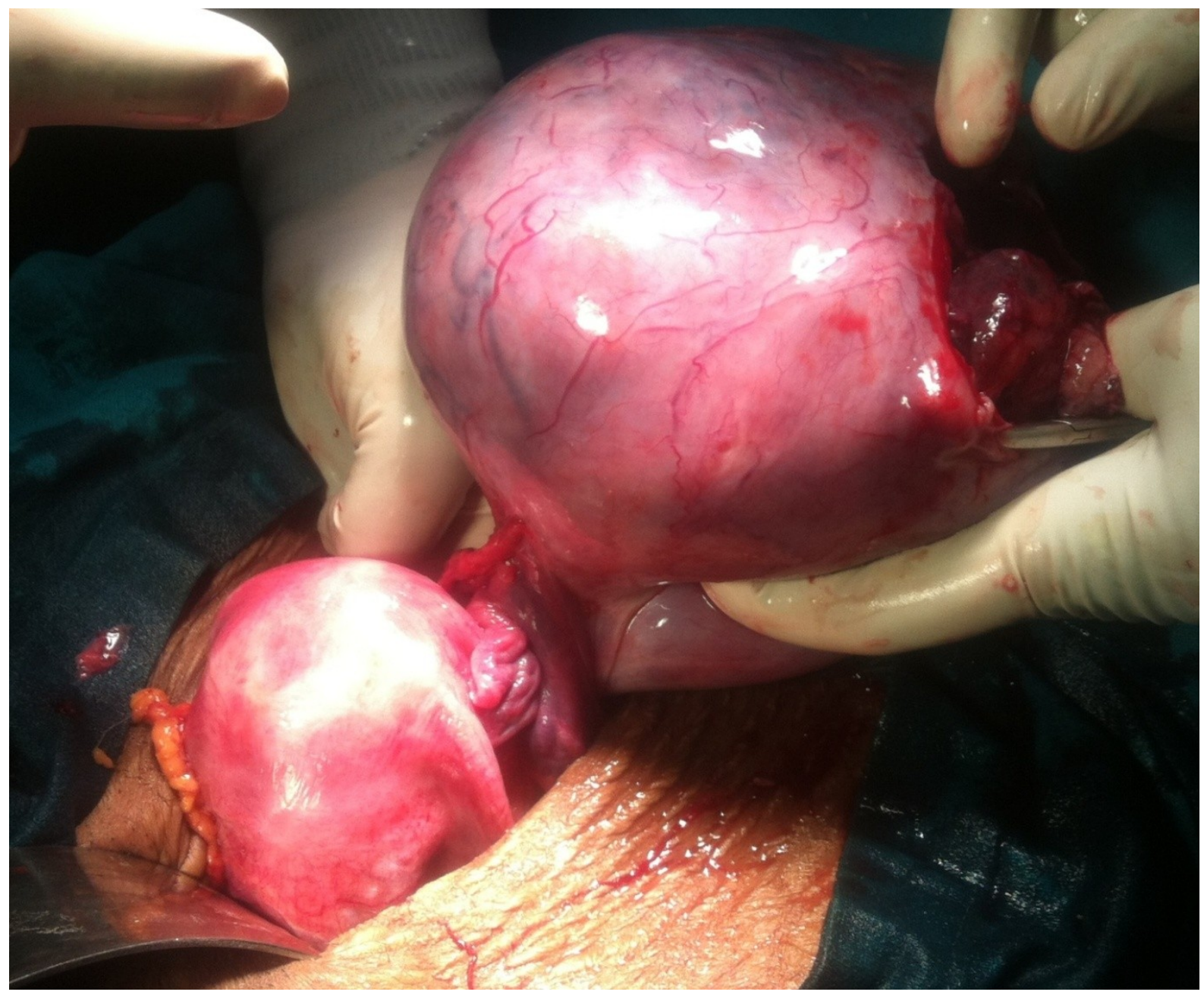

Fig 1: Intraoperative picture showing left ovarian dysgerminoma.

On cut section, the mass appeared multiloculated cyst with interspersed solid components of variegated consistency. The cystic fluid was seromucinous with hemorrhagic components. On microscopy, the tumor cells appeared to be arranged in nests, cords, sheets and pseudoglandular pattern separated by fibrous septa and sparse lymphocytic infiltrate. The individual tumor cells were round to oval with centrally placed large nucleus and nucleoli. The cytoplasm was finely granular and vacuolated with evidence of mitosis and tumor giant cell at places. An impression of germ cell tumor of ovary, dysgerminoma was made. Immunohistochemistry was suggested for confirmation and to rule out mixed tumor variant. The biopsy from other ovary, peritoneal surface, omentum and paraarotic lymph nodes were negative for malignancy. 


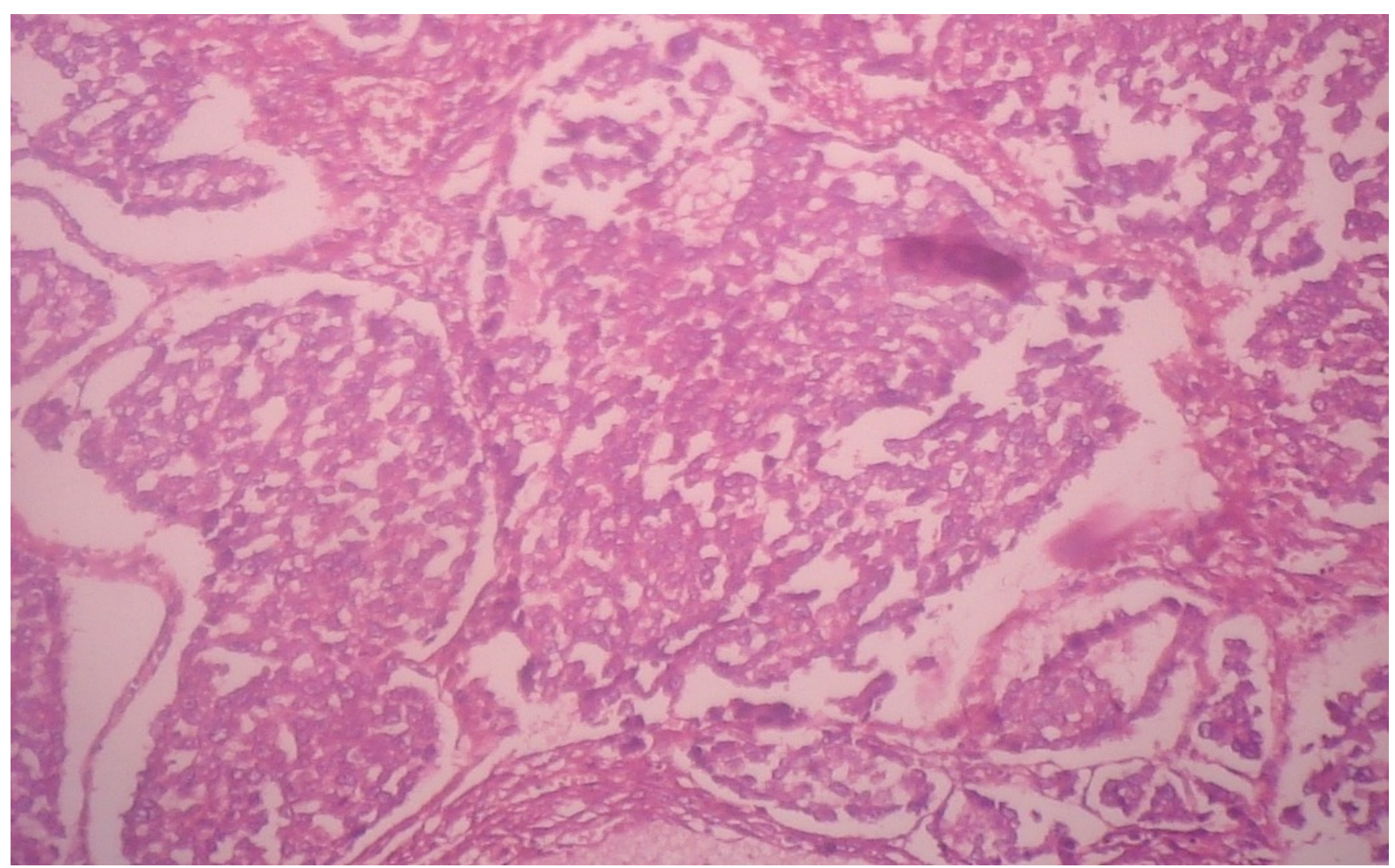

Fig 2. Low-power view showing lobular pattern and septae

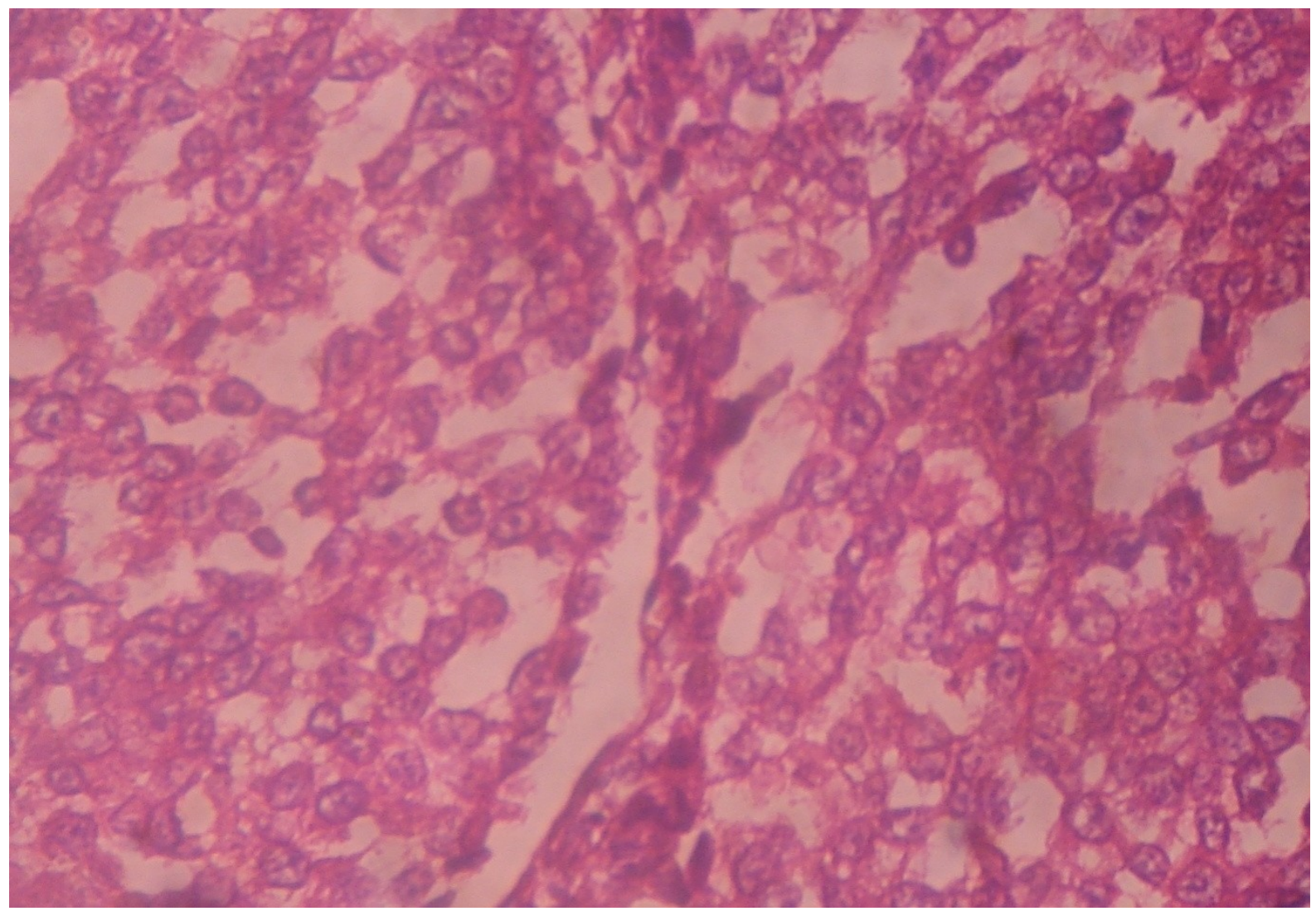

Fig. 3: High power view showing lymphocytic infiltrations 


\section{Discussion:}

Amenorrhoea, abnormal vaginal bleeding and positive pregnancy test with an adnexal mass in a woman of reproductive age group commonly raise a suspicion of ectopic pregnancy. The differentials of such a clinical presentation suggestive of ectopic pregnancy, although rare are many and include corpus luteal cyst, functional cyst,parovarian cyst, endometrioma, leiomyoma and ovarian neoplasms with pregnancy. A thoughtful consideration of these differentials would be desirable in individual case to plan out appropriate management.

The incidence of adnexal masses in association with pregnancy has been variously reported as 1 in 80 to 1 in 8000 pregnancies. ${ }^{3}$ Hirota et al, in their study reported that frequency of ovarian tumor in such adnexal masses concurrent with pregnancy ranges from 1 in 80 to 1 in 2200 deliveries. ${ }^{4}$ The rate of malignancy in such tumors is extremely low and has been reported to vary between 1 and $8 \%$ in different studies. , $^{3,6}$ Dysgerminoma, the malignant germ cell ovarian tumor is very rarely reported in association with pregnancy. ${ }^{7,8}$ In a study by Ueda $\mathrm{M}$ et al of 106 cases of ovarian tumors associated with pregnancy who underwent surgery, five $(4.7 \%)$ were malignant. Dermoid was the commonest lesion while dysgerminoma was noted in only one case. $^{9}$

About $75 \%$ of dysgerminoma affect the women below 30 years of age and they are extremely rare after the age of 50.,10,12 Lee et al reported the mean age of women in their study as 23.8 years ( Range 4-63 years )$^{11}$, a finding similar to our case. Most of the ovarian neoplasms are asymptomatic and are often diagnosed on clinical examination or picked up on grey scale sonography. With increasing use of sonography the ovarian tumors are being detected more frequently during pregnancy. Among the symptomatic ones, the women commonly present with abdominal mass or distension due to the presence of mass itself or the ascitis. Abdominal discomfort with variable degree of pain may occur in cases of hemorrhage, capsule distension, rupture or torsion. Pressure symptoms or symptoms related to hormone excess (estrogen, androgens, $\beta$-hCG) are the other reasons for which these women seek gynaecological consultation. In our case, the woman presented with gradual abdominal distension, amenorrhoea and abnormal bleeding per vaginum. Although the mass could be appreciated on careful abdominal examination, its extent and characteristics were better delineated after sonographic examination. In young patients, the early symptoms of tumor can be mistaken for pregnancy which could have been possible in our case for delay in reporting. Antoshechkina et al in their study of ovarian dysgerminoma reported pain as the most frequent symptom $(70 \%)$ while acute appendicitis and pregnancy were the most frequent misdiagnoses. ${ }^{12}$

As the germ cell malignancies predominantly affect young women, they may co-exist with pregnancy.Pregnancy, may not alter the prognosis of ovarian tumor but torsion and incarceration can occur with these rapidly growing tumors. The natural course of pregnancy with dysgerminoma is rare with obstetrical complications occurring in nearly half and pregnancy loss or fetal demise affecting quarter of cases. ${ }^{7} \mathrm{Kafil}$ akhtar et al, however reported a case of successful spontaneous pregnancy in a primigravidae associated with dysgerminoma and no fetomaternal compromise. ${ }^{13}$ Similarly Agrawal A et al reported an unusual case of stage 3C dysgerminoma in a young woman presenting as acute abdomen at 33 weeks of gestation. ${ }^{8}$ The concerns are not just about the effect of malignancy on the natural course of pregnancy but also about implementing the appropriate management during pregnancy. Because of the rarity, most of the recommendations are drawn extrapolations from the experience with their corresponding testicular tumors and clear cut recommendations regarding their management in pregnancy are lacking. Karlen JR in their review of 26 cases of dysgerminoma associated with pregnancy strongly discouraged conservative management with $30 \%$ cases of stage $1 \mathrm{~A}$ tumors treated by unilateral oopherectomy having recurrence. ${ }^{7}$ They were of the opinion that a young woman with dysgerminoma and pregnancy poses clinical dilemma yet conservative surgeries should be limited to women desirous of future childbearing only. Early diagnosis and prompt excision of ovarian lesion while it is still intact by laparotomy or laparoscopically offers the best materno-fetal outcome irrespective of gestational age. ${ }^{14,15}$ In young women with tumor confined to one ovary, Conservative surgery followed by adjuvant therapy or close follow up at regular intervals can be attempted to preserve fertility. The concerns about the spread of malignancy with conservative surgeries and teratogenicity of antineoplastic agents are speculated when conservative approach is opted for. Dysgerminoma, although very sensitive to radiation and chemotherapy both, loss of fertility is a problem with radiation. Thus, chemotherapy is preferred over radiotherapy in such cases and can be administered during second and third trimesters without apparent detriment to the fetus. ${ }^{10}$ Kim and park reported delivery of a normal infant following the use of chemotherapeutic agents in second triemester. ${ }^{16}$ Our patient was advised close follow up in terms of regular pelvic examination and abdominal CT scan as there was no evidence of metastasis and complete resection of tumor mass was possible in our case.

Management of young women with dysgerminoma is often associated with concerns about possible reduction in fertility. However, there are several case reports of pregnancies following dysgerminoma treatment in the literature. ${ }^{17}$ There are even reports of pregnancy in phenotypic females with gonadal dysgenesis who were treated for dysgerminoma. ${ }^{18,19}$ 
Grey scale sonography with Doppler studies is preferred modality for primary evaluation and prediction of malignancy when an adnexal mass is detected on clinical examination. Although, the classic tissue characteristics of dysgerminoma on sonography have not been extensively reported in the literature, the color Doppler often shows prominent arterial flow within the fibro vascular septa with a resistive index value ranging from 0.44 to $0.70 .{ }^{20}$ On CT and MRI, the tumor has been typically described as a multilobulated solid mass with lobules divided by fibrovascular septa. The size of mass, cystic with solid components, thick septations and ascitis helped to rule out other differentials and pointed toward ovarian malignancy in our case.

The values of tumor markers should be interpreted with caution during pregnancy as there is wide variation in results and poor specificity during pregnancy. Some authors, in fact advocate not to take management decisions based on single tumor marker values in cases of asymptomatic non complex masses during pregnancy. ${ }^{21} \mathrm{The}$ primary role of tumor markers is in following the levels as a marker of tumor control. In our case, serum CA 125 and LDH values were mildly elevated while alfa fetoprotein levels were normal. Serum $\beta$-hCG levels are rare to be elevated in cases of dysgerminoma, as in cases of mixed variant or with infiltration of syncytiotrophoblastic giant cell. Elevated serum $\beta$-hCG levels in our case reflected the rise due to pregnancy.

Ovarian germ cell tumors, unlike the epithelial variety grow rapidly yet most of the patients usually present early when the disease is limited to the ovary (stage 1).Quirk and Natarajan in their study reported that roughly $75 \%$ of women presented in stage 1a which was similar to our finding. ${ }^{22}$ Similarly, Antoshechkina ET reported stage 1 tumor in nearly $70 \%$ of cases in their study of 80 cases. They also commented that stage and size of neoplasm had the highest prognostic value. ${ }^{12}$ Dysgerminomas are usually associated with excellent prognosis with reported 5-year survival rate being greater than $95 \%$ for tumors confined to the ovary and about 60 to $80 \%$ for advanced staged or recurrent tumors. ${ }^{23}$ The pathologic type and stage of tumor seem to be important prognostic determinants. Chemotherapy consisting of four cycles of BEP regimen offers optimum treatment for residual or recurrent disease. Our patient is under constant follow up and currently free of disease. Conclusion: Adnexal masses in pregnancy quite often detected incidentally are rare occurrence and involve a gamut of differential diagnosis. A thoughtful consideration of all and stepwise exclusion one by one can help tailor the management in individual case.

\section{References}

[1]. Zalel Y, Piura B, Elchalal U, Czernobilsky B, Antebi S,Dgani R. Diagnosis and management of malignant germ cell ovarian tumors in young females.Int J Gynaecol Obstet 1996; 55: 1-10

[2]. Zaloudek C.The ovary. In: Gompel C, Silverberg SG (eds).Pathology in Gynecology and Obstetrics. Philadelphia, PA: JB Lippincott Co; 1994: $379-397$

[3]. Whitecar P, Turner S, Higby K. Adnexal masses in pregnancy: a review of 130 cases undergoing surgical management. Am J Obstet Gynecol 1999;181: 19- 24

[4]. Hirota Y, Sawada T, Kumayama M. Clinical study on ovarian malignant tumors associated with pregnancy. Rinsho Fujinka Sanka $1991 ; 45: 1331-1335$

[5]. Leiserowitz G.Managing ovarian masses during pregnancy. Obstet Gynecol Surv 2006; 61: 463-70

[6]. Schmeler K, Mayo-Smith W, Peipert J, Weitzen S, Manuel M, Gordinier M. Adnexal masses in pregnancy: surgery compared with observation. Obstet Gynecol 2005; 105: 1098-103

[7]. Karlen JR, Akbari A, Cook WA. Dysgerminoma associated with pregnancy. Obstet Gynecol 1979; 38(1): 111-6

[8]. Agrawal A, Rijal P, Pokharel H, Karki S, Basnet P, Dahal P. Ovarian dysgerminoma : Unusual Presentation in Pregnancy with Acute Abdomen due to Internal Hemorrhage. NJOG 2012 Jan- June; 7(3): 53-55

[9]. Ueda M, Ueki M. Ovarian tumors associated with pregnancy. Int J Gynecol Obstet 1996. Oct; 55(1): 59-65. doi: 10.1016/00207292(96)02718-X.

[10]. Jonathan S. B., Sathima Natrajan. Ovarian and Fallopian Tube Cancer. In: Jonathan S. berek, eds. Berek \& Novak's Gynaecology. 14th ed. Philadelphia,PA: LIPPINCOTT WILLIAMS \& WILKINS; 2007: 1504-1513.

[11]. Lee KH, Lee IH, Kim BG, Nam JH, Kim WK, Kang SB et al. Clinicopathologic characteristics of malignant germ cell tumors in the ovaries of Korean women: a Korean Gynecologic Oncology Group Study. Int J Gynecol Cancer.2009;19: 84-7.

[12]. Antoshechkina ET.Clinical picture and treatment of ovarian dysgerminoma patients. Vopr Onkol, 1985;31(3): 68-74

[13]. Kafil Akhtar, S. Shamshad Ahmad, Amit Kumar and Noor Afsan. Dysgerminoma with Pregnancy and Viable Baby:A Case Report. Oman Med J. 2011 May; 26 (3): 198-200

[14]. Hill LM, Johnson CE, Lee RA. Ovarian surgery in pregnancy. Am J Obstet Gynecol 1975. Jul;122(5):565-569.

[15]. Matsuyama T, Tsukamoto N, Matsukuma K, Kamura T, Kaku T, Saito T. Malignant ovarian tumors associated with pregnancy: report of six cases. Int J Gynaecol Obstet 1989. Jan;28(1):61-66. doi: 10.1016/0020-7292(89)90545-6.

[16]. Kim DS, Park MI. Maternal and fetal survival following surgery and chemotherapy of endodermal sinus tumor of the ovary during pregnancy: a case report. Obstet Gynecol 1989. Mar;73(3 Pt 2):503-507.

[17]. McCarthy TG, Milton PJ. Successful pregnancy after conservative surgery and radiotherapy for dysgerminoma of the ovary.Br J Obstet Gynecol.1975 Jan; 82(1): 64-7

[18]. Tanaka Y, Fujiwara K, Yamauchi H, Mikami Y, Kohno I. Pregnancy in a woman with a Y chromosome after removal of an ovarian dysgerminoma. Gynecol Oncol. 2000 Dec;79(3):519-21.

[19]. Talerman A, Verp MS, Senekjian E, Gilewski T, Vogelzang N. True Hermaphrodite With Bilateral Ovotestes, Bilateral Gonadoblastomas and Dysgerminomas, 46, XX/46, XY Karyotype, and a Successful Pregnancy. Cancer 1990.Dec;12:2668-2672

[20]. Kim HS, Kang BS.Ovarian Dysgerminoma: color Doppler ultrasonographic findings and comparison with CT and MR imaging findings. J Ultrasound Med 1995; 14:843-848

[21]. Kim Hoover, Todd R. Jenkins. Evaluation and management of adenexal mass in pregnancy. Am J Obstet Gynecol 2011. Aug;205:(2),97102. Doi:10.1016/j.ajog.2011.01.050

[22]. Quirk JT, Natarajan N. Ovarian cancer incidence in the United States, 1992-1999. Gynecol Oncol 2005. May;97(2):519-523. doi: 10.1016/j.ygyno.2005.02.007.

[23]. Noam Lazebnik, Anna Balog. Ovarian Dysgerminoma: A challenging clinical and sonographic Diagnosis. J Ultrasound Med 2009; 28:1409-1415 